\title{
A Single Allatostatin-Immunoreactive Neuron Innervates Skeletal Muscles of Several Segments in the Locust
}

\author{
SABINE KREISSL, ${ }^{1}$ CLAUDIA C. SCHULTE, ${ }^{1}$ HANS-JÜRGEN AGRICOLA, ${ }^{2}$ \\ AND WERNER RATHMAYER ${ }^{1 *}$ \\ ${ }^{1}$ Department of Biology, University of Konstanz, D-78457 Konstanz, Germany \\ ${ }^{2}$ Biologisch-Pharmazeutische Fakultät, University of Jena, D-07743 Jena, Germany
}

\begin{abstract}
In the nervous system of embryos and adult Locusta migratoria, somata, neurites within the ganglia, and axons leaving the thoracic ganglia show allatostatin immunoreactivity. The immunoreactive efferent axons divide to follow different nerve branches and form varicose terminals on skeletal muscles. In the adult locust, one pair of motor neurons is particularly prominent among the allatostatin-immunoreactive neurons. The somata are located symmetrically in a lateral position in the first abdominal neuromere of the fused metathoracic ganglion. Each neuron gives rise to five axon branches projecting into ipsilateral nerves. Three axons project posteriorly and exit through the dorsal nerves of the abdominal neuromeres A1, A2, and A3. One axon extends into the metathoracic neuromere and exits through metathoracic nerve 1 (N1). The fifth axon extends anteriorly through the connective into the mesothoracic ganglion, where it leaves through the mesothoracic N1. The targets of this neuron, among them the mesothoracic and metathoracic muscles M87, M88, M116 and the dorsal longitudinal muscles M81 and M112, are located in five different segments. In addition to supplying skeletal muscles, the neuron forms neurohaemal-like structures in the sheath of nerve branches. The authors call this neuron the common lateral neuron (CLN). The innervation of several muscles by Diploptera allatostatin 7-immunoreactive axon branches with a common cellular origin and the anatomy of one of the corresponding motor neurons in adults, the CLN, suggest that allatostatin acts as a modulator of neuromuscular parameters in insects by multisegmental direct innervation of skeletal muscles. J. Comp. Neurol. 413:507-519, 1999. (1) 1999 Wiley-Liss, Inc.
\end{abstract}

Indexing terms: Locusta migratoria; neuropeptide; insect nervous system; neuromodulation; identified motor neuron

The sparse innervation of arthropod skeletal muscles by very few motor neurons is compensated functionally by the presence of modulatory neurons that synthesize and release small peptides or biogenic amines, which influence the efficiency of motor neuron signaling at the target muscles. The modulatory substances are released either from neurohaemal sites and circulated to their targets through the haemolymph or directly onto the muscle fibers from neuromuscular endings (for review, see Rheuben, 1995). The constantly growing literature on the occurrence, distribution, and functions of more than 300 peptides alone in insects has been reviewed extensively (Penzlin, 1989; Masler et al., 1993; Nässel, 1996a,b; Gäde et al., 1997; Schoofs et al., 1997).

Most of these peptides have excitatory effects on their targets. Proctolin and the FMRFamide-related peptides have been studied most extensively. Proctolin increases the basal tonus of muscles and potentiates through several mechanisms the contraction of visceral and skeletal muscles in insects and crustaceans-either when they are produced myogenically, by activity of motor neurons, or when they are elicited by direct depolarization of muscle fibers (Piek and Mantel, 1977; May et al., 1979; Evans, 1984; Cook and Holman, 1985; Evans and Myers, 1986a; O'Shea and Adams, 1986; Orchard et al., 1989; Baines et

Grant sponsor: Deutsche Forschungsgemeinschaft; Grant numbers: DFG: SFB 156 B5 and Ra 113/8-1.

Claudia C. Schulte's current address is: Department of Otolaryngology, University of Tübingen, D-72076 Tübingen, Germany.

*Correspondence to: Dr. Werner Rathmayer, Department of Biology, University of Konstanz, D-78457 Konstanz, Germany.

E-mail: werner.rathmayer@uni-konstanz.de 
al., 1990; Erxleben et al., 1995; Facciponte et al., 1995). Most FMRFamide-related peptides also potentiate contractions of arthropod visceral and skeletal muscles (Walther et al., 1984; Evans and Myers, 1986b; Robb et al., 1989; Robb and Evans, 1990; Evans, 1994; Lange et al., 1994; Hewes et al., 1998). Similar to what is seen with proctolin, several mechanisms are involved in producing these effects (Worden et al., 1995; Hewes et al., 1998; Walther et al., 1998).

Proctolin is contained in a few identified motor neurons and is released as a cotransmitter with glutamate or $\gamma$-aminobutyric acid (GABA) directly on the muscle fibers (O'Shea and Bishop, 1982; Adams and O'Shea, 1983; Bishop et al., 1984, 1987; Keshishian and O'Shea, 1985a; Witten and O'Shea, 1985; Evans et al., 1989; Bartos et al., 1994). Within the central nervous system (CNS), FMRFamide-related peptides are localized in interneurons and also in some efferent neurons. The peptides are believed to be released mainly from neurohaemal organs into the haemolymph (Schiebe et al., 1990; Wall and Taghert, 1991; Elia et al., 1993; Schneider et al., 1993; Miksys et al., 1997). Some of the efferent neurons supply visceral muscles, such as those of the oviduct and the intestine in insects and crustaceans (Myers and Evans, 1985; Evans and Myers, 1986b; Mangerich and Keller, 1988; Walther and Schäfer, 1988; Miao et al., 1998). Recently, motor neurons containing FMRFamide-related peptide and directly supplying somatic muscles of the cockroach and Drosophila were described (Elia and Orchard, 1995; Hewes et al., 1998).

Inhibitory effects on muscle function have been shown to be exerted by allatostatins, another well-studied family of arthropod peptides. Allatostatins originally were isolated from brains of the cockroach Diploptera punctata (therefore termed Dip-AST), where they inhibit the biosynthesis of juvenile hormone in the corpora allata (Pratt et al., 1989). Subsequently, more than 50 different allatostatins sharing the C-terminal sequence YXFGL have been found in central neurons of a large number of insects (for reviews, see Stay et al., 1994; Bendena et al., 1997; Gäde et al., 1997) and another 20 allatostatins in crustaceans (Duve et al., 1997). In insects, allatostatins inhibit spontaneous and neurally evoked contractions of the foregut and hindgut (Lange et al., 1993, 1995; for reviews, see Stay et al., 1994; Bendena et al., 1997). In the crab Cancer borealis, allatostatin slows the stomatogastric rhythm and decreases the gain of neuromuscular transmission at stomach muscles (Skiebe and Schneider, 1994; JorgeRivera and Marder, 1997). In the isopod Idotea, allatostatin occurs in a few identified motor neurons. It exerts a twofold complementary inhibitory action on neuromuscular parameters: presynaptically, it reduces evoked transmitter release from excitatory nerve terminals, and, postsynaptically, it decreases the amplitude of muscle contractions (Kreissl et al., 1999). Recently, allatostatin immunoreactiv-

\section{Abbreviations}

$\begin{array}{ll}\text { A1, A2, A3 } & \text { first, second, third abdominal neuromere } \\ \text { CLN } & \text { common lateral neuron } \\ \text { Dip-AST 7-ir } & \begin{array}{l}\text { Diploptera-allatostatin 7-immunoreactive } \\ \text { DUM }\end{array} \\ \text { dorsal unpaired median } \\ \text { M } & \text { muscle } \\ \text { N } & \text { nerve } \\ \text { T1, T2, T3 } & \text { pro-, meso-, metathoracic ganglion }\end{array}$

ity also was shown in motor neurons supplying thoracic and maxillary muscles in larvae of the moth Manduca sexta, suggesting that here, too, its effect is not restricted to visceral muscles (Davis et al., 1997). This immunoreactivity, however, disappears early in pupal development of Manduca.

In wholemounts of grasshopper embryos, we detected Dip-AST 7 immunoreactivity in the CNS in neurons, in intrinsic neurites, and in some axons leaving the thoracic ganglia. Single axons branch profusely and form varicosities on several target muscles, providing common immunoreactive innervation. To find the cellular origin of this peptidergic motor innervation, we employed adult locusts and carried out backfills from muscles known to receive Dip-AST 7-immunoreactive (Dip-AST 7-ir) axons in the embryo. We focused on the innervation of muscles for which the complete set of motor neurons has been described previously (Kutsch and Schneider, 1987; Breidbach and Kutsch, 1990; Kutsch and Heckmann, 1995; Steffens and Kutsch, 1995).

We found a number of skeletal muscles with Dip-AST 7 -ir varicosities also in the adult, suggesting a role for allatostatin in the modulation of neuromuscular parameters in the locust. Part of this modulation is exerted by a new type of common unilateral motor neuron innervating dorsal and ventral muscles that are located in five segments. Because this Dip-AST 7-ir neuron has several targets, and because of the lateral position of the soma, we term this neuron the common lateral neuron (CLN). Some of these results have been published in abstract form (Kreissl et al., 1995; Schulte et al., 1996).

\section{MATERIALS AND METHODS Immunocytochemistry}

All experiments were performed on embryonic and adult Locusta migratoria of either gender from a crowded colony maintained in Konstanz. All protocols used in this study were approved by the Animal Care and Use Committee of the University of Konstanz and conformed to German laws on the protection of animals. For immunocytochemical detection of Dip-AST 7-ir central neurons and peripheral innervation of skeletal muscles, embryos of $L$. migratoria were used initially as an assay. The embryos at different stages (staging after Bentley et al., 1979) were pealed off of their chorion after chilling, and the legs and mandibles were removed. By opening the embryo in a dish filled with artificial saline (composed of $150 \mathrm{mM} \mathrm{NaCl}, 3 \mathrm{mM} \mathrm{KCl}, 2$ $\mathrm{mM} \mathrm{CaCl} 2,1 \mathrm{mM} \mathrm{MgSO} 4,5 \mathrm{mM} \mathrm{N}$-tris(hydroxymethyl)methyl-2-aminoethanesulfonic acid (TES), $10 \mathrm{mM}$ trehalose, and $40 \mathrm{mM}$ glucose, $\mathrm{pH}$ 7.0) through a cut on the dorsal midline, the intestine and the yolk could be removed easily. The specimens were pinned ventral side down in a Sylgard-coated Petri dish and subsequently fixed in $4 \%$ paraformaldehyde (PFA) in $0.1 \mathrm{M}$ phosphate buffer, $\mathrm{pH}$ 7.4 , for $1-2$ hours at room temperature.

Allatostatin was identified in neurons by using a polyclonal antiserum characterized by Vitzthum et al. (1996). This antiserum was generated against an allatostatin with the amino acid sequence APSGAQRLYGFGL-NH $\mathrm{N}_{2}$. Those authors used the term Dip-AST I for this isoform, which is now termed Dip-AST 7 (Gäde et al., 1997). The specificity of this antiserum was determined by using a competitive electron lucent immunosorbent assay and was shown to be nearly 2 orders of magnitude more sensitive to Dip-AST 7 than to other allatostatin isoforms. Preadsorp- 

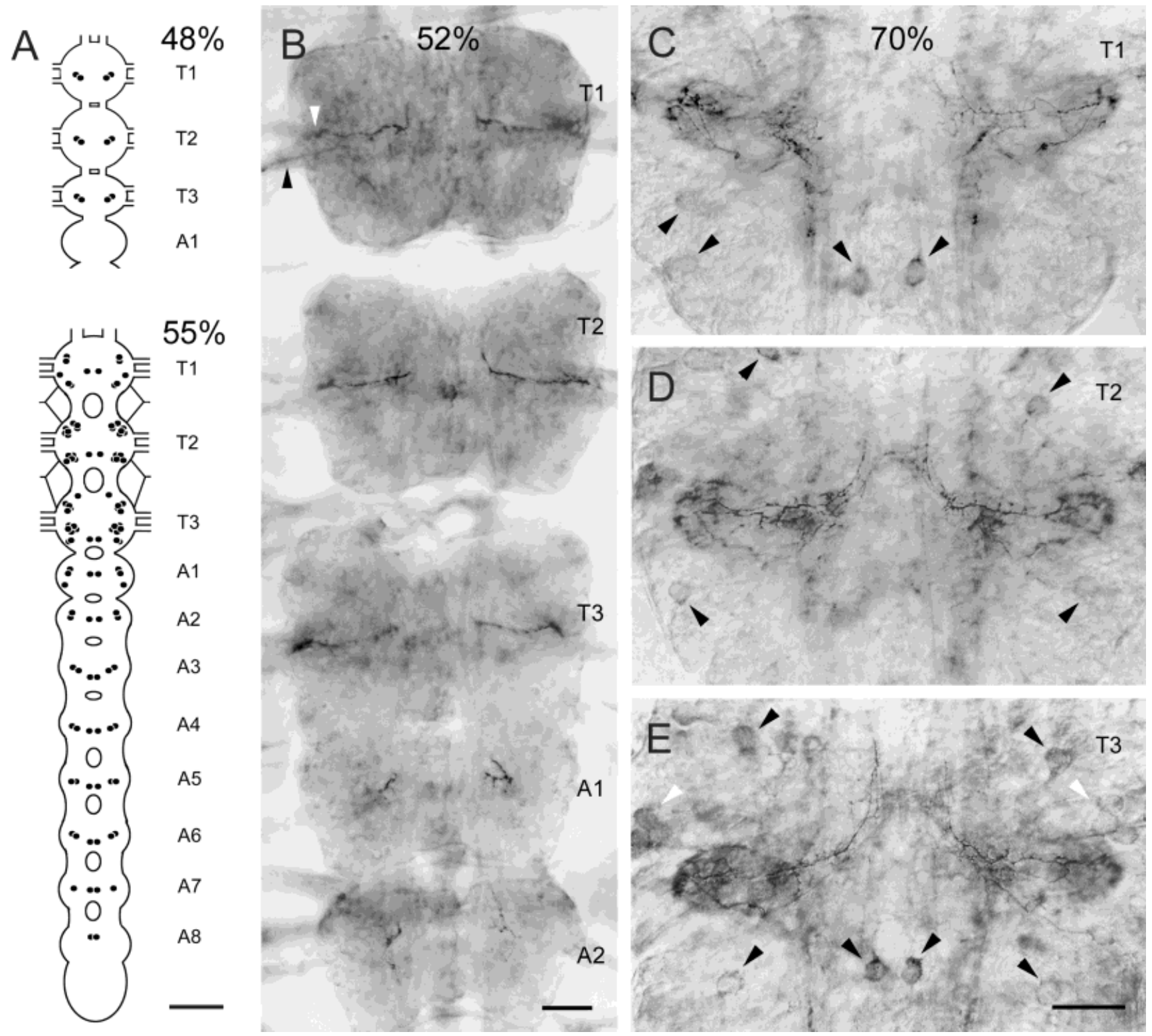

Fig. 1. Diploptera allatostatin 7 (Dip-AST 7) immunoreactivity in the central nervous system of locust embryos. A: Schematic representation of Dip-AST 7-immunoreactive (-ir) somata in embryos at $48 \%$ and 55\% of development. B: Ventral view of the three thoracic and two abdominal ganglia at $50 \%$ of development. Several axons are stained in each ganglion. In this plane of focus, one stained axon exits the

prothoracic ganglion (T1) through the fourth nerve (N4; black arrowhead), and another extends toward N3 (white arrowhead). C-E: Dip-AST 7-ir axons, somata (black arrowheads), and groups of somata (white arrowheads) in T1, mesothoracic ganglion (T2), and metathoracic ganglion (T3) at 70\% of development. A1-A8, abdominal ganglia 1-8. Scale bars $=200 \mu \mathrm{m}$ in A; $50 \mu \mathrm{m}$ in B-E.

tion of the diluted antiserum with $10 \mu \mathrm{M}$ Dip-AST 7 abolished all immunostaining (Vitzthum et al., 1996).

After several rinses with $0.01 \mathrm{M}$ phosphate-buffered saline (PBS) with $160 \mathrm{mM}$ Nacl, $\mathrm{pH} 7.6$, containing $0.5 \%$ Triton X-100 (PBSX 0.5), the embryos or ganglia were incubated in a 1:1,000 dilution of the polyclonal Dip-AST 7 antiserum in PBSX 0.5 with $0.2 \%$ bovine serum albumin (BSA; Sigma, Deisenhofen, Germany). After washing with PBSX 0.1, the tissue was incubated in a 1:500 dilution of an indocarbocyanin (Cy3)-conjugated goat-anti-rabbit immunoglobulin G (IgG; Dianova, Hamburg, Germany) overnight. Extended washing with $0.1 \mathrm{M}$ Tris/HCl, $\mathrm{pH}$ 7.4, was followed by mounting the preparations in $90 \%$ glycerol.

For wholemount staining of Dip-AST 7 immunoreactivity in adult animals, ganglia were excised, fixed in 4\% PFA for 2-3 hours, and processed like the embryos. To obtain the total number of stained somata in thoracic ganglia, serial sections were made. Excised ganglia were embedded in Paraplast after fixation, washed, and dehydrated in an alcohol series. Sections were cut in sagittal or vertical planes at $12 \mu \mathrm{m}$ and mounted on slides. The sections were deparaffinized, and Dip-AST 7 immunoreactivity was detected with the polyclonal antiserum at a dilution of 1:20,000. For detection of primary antiserum binding, either immunofluorescence (as described in the wholemount protocol described above for embryos) or the avidin- 
biotin complex (ABC) method (ABC kit; Vector Laboratories, Burlingame, CA) were used. In the latter case, after washing with PBS, the peroxidase labeling was visualized by using diaminobenzidine (DAB)/NiCl as the chromogen $\left(0.005 \% \mathrm{DAB}, 0.02 \%, \mathrm{NiCl}\right.$, and $0.00015 \% \mathrm{H}_{2} \mathrm{O}_{2}$ in $0.1 \mathrm{M}$ phosphate buffer, pH 7.6) as a substrate solution. Skeletal muscles from adults were stained by using the wholemount protocol described for ganglia of adult locusts. Some muscles were cut on a cryostat after fixation and washing and were treated subsequently with the Dip-AST 7 antiserum and the Cy3-conjugated goat-anti-rabbit IgG for detection of antibody binding.

\section{Backfills}

For retrograde labeling of motor neurons, the adult animal was decapitated, and the abdomen and gut were removed. To expose the relevant ganglia and the peripheral nerve branches, the thorax was opened with a cut along the dorsal midline and mounted with the ventral surface down in a silicone-coated dish. The preparation was superfused with artificial saline. The muscles and nerves leaving the ganglia were identified according to Albrecht (1953) and Campbell (1961), respectively. The nerve branches innervating muscles were cut at the point of contact with the muscle. In some cases and for retrograde labeling of motor neurons in embryos, an excised piece of the muscle with the supplying nerve attached was used. A small Vaseline pot surrounded the cut nerve in both types of preparations. The pot was filled first with distilled water for 3 minutes and subsequently with a $4 \%$ solution of neurobiotin (Vector Laboratories) in distilled water. Diffusion and transport were allowed to continue for 12 hours at $8^{\circ} \mathrm{C}$. The ganglia were then rapidly excised. Embryos or ganglia were fixed in 4\% PFA. After washing and permeabilizing with PBSX 0.5, the specimens were incubated with an avidin-conjugated fluorescein isothiocyanate (Sigma) diluted 1:200 in PBSX 0.1. After washing with $0.1 \mathrm{M}$ Tris/ $\mathrm{HCl}, \mathrm{pH} 7.4$, the tissue was dehydrated in $100 \%$ glycerol containing $1 \%$ n-propyl-gallate to retard photobleaching and mounted on coverslips. The ganglia were examined under fluorescence before being processed further. Some ganglia were embedded in Paraplast. Sections were cut in sagittal or vertical planes at $12 \mu \mathrm{m}$. The sections were deparaffinized, cleared with xylene, and mounted in Entellan (Merck, Darmstadt, Germany).

To obtain permanent stainings of the CLN, some ganglia were incubated in avidin-biotin-horseradish peroxidase complex (Vector Laboratories) and developed by using $\mathrm{DAB}$ as described for the immunostaining protocol. After the final rinse, the tissue was again dehydrated, cleared in methylsalicylate, and mounted between glass coverslips.

\section{Double labeling}

Ganglia in which backfills were obtained were rehydrated. Nonspecific binding was blocked by incubation in $0.2 \%$ BSA in PBSX 0.5, and Dip-AST 7 immunostaining was performed subsequently. The wholemounts were viewed by using two different selective filters to determine double-labeled neurons.

All results are based on at least three observations. The wholemounts and sections were viewed with an inverse microscope (Axiovert; Zeiss, Stuttgart, Germany), drawn with the aid of a camera lucida device, and photographed. Numbers of immunostained somata were counted in drawings of serial sections of three sets of mesothoracic and

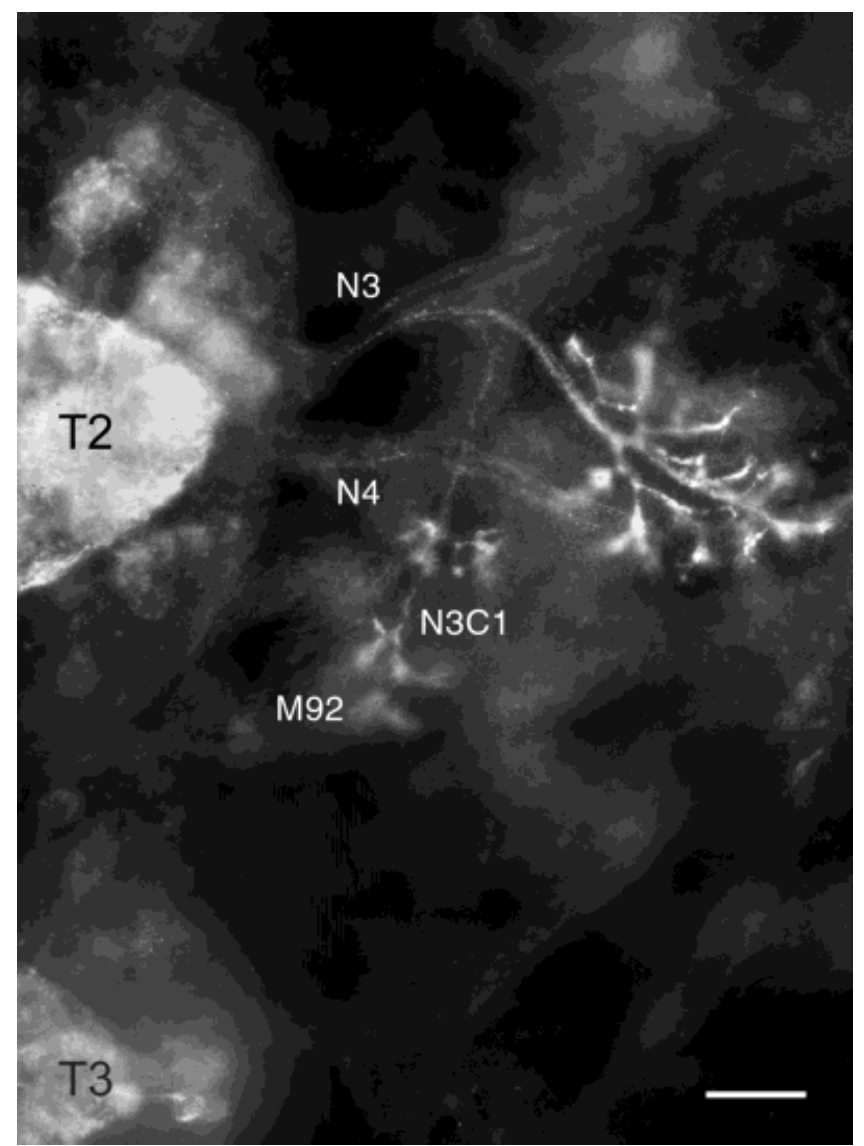

Fig. 2. Dip-AST 7-ir innervation of ventral thoracic muscles and immunoreactive somata in T2 and T3 of an embryo at $55 \%$ of development. Prior to fluorescence microscopy, muscles were identified by viewing the preparation with Nomarski interference contrast optics. Muscle 92 (M92), which is hardly recognizable with fluorescence microscopy, receives Dip-AST 7-ir innervation through N3C1 by a branch from an axon leaving T2 through N3. This axon also supplies other muscles in the coxa. Anterior is at the top, and the ventral midline is on the left. Scale bar $=50 \mu \mathrm{m}$.

metathoracic ganglia. Composite figures were generated after scanning the drawings and color slides on a computer by using Adobe Photoshop image-enhancement and processing software (version 5; Adobe Systems, Mountain View, CA). The double staining was recorded digitally with a Hamamatsu video system.

\section{RESULTS \\ Development of Dip-AST 7 immunoreactivity in the CNS and on skeletal muscles}

The first appearance of Dip-AST 7 immunoreactivity in the CNS of L. migratoria was detected at $43 \%$ of embryonic development. A pair of Dip-AST 7-ir cell bodies with contralaterally projecting neurites was present in the protocerebrum. At this stage, no immunoreactive cell bodies could be detected in thoracic or abdominal ganglia in wholemounts or in sections. However, two growth cones extending bilaterally toward the dorsal surface in each thoracic ganglion already were stained. At $45-50 \%$ of development, a pair of Dip-AST 7-ir somata appeared laterally in each thoracic ganglion (Fig. 1A). Several 


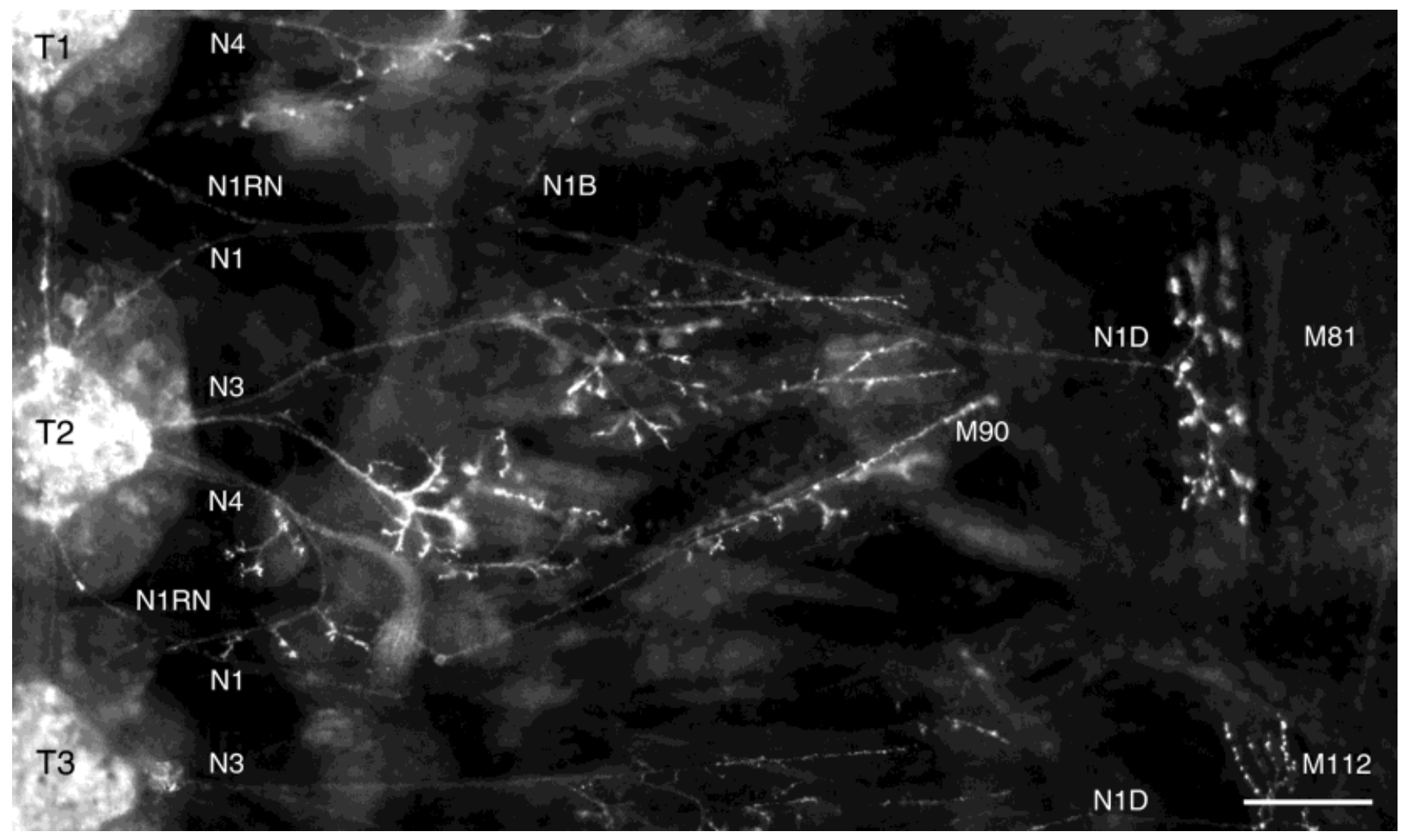

Fig. 3. Dip-AST 7-ir innervation of thoracic muscles in an embryo at $70 \%$ of development. An immunoreactive axon leaves T2 through N1. It supplies the dorsal longitudinal muscle M81 of the mesothoracic segment through N1D and projects anteriorly to other targets through

immunoreactive growth cones extended toward the roots of the third and fourth nerves (N3 and N4) of the thoracic ganglia (Fig. 1B).

At 50-60\% of development, several other small groups of immunoreactive neurons appeared bilaterally and medially in both the ventral part and the dorsal part of the thoracic and abdominal ganglia (Fig. 1A). Among these, two median and two lateral immunoreactive somata were prominent in each thoracic and abdominal ganglion. The latter send their primary neurites to the contralateral side. Their axons travel anteriorly along the connectives and form arborizations within the ganglia. Figure $1 \mathrm{C}-\mathrm{E}$ shows typical staining patterns of the three thoracic ganglia in an embryo at $70 \%$ of development.

At 55\% of development, two Dip-AST 7-ir branches are present in all N3 and N4 of the thoracic ganglia. Single immunoreactive axons arborize and contact different developing thoracic muscles (Fig. 2) and different leg muscles in the coxa, femur, and tibia and begin forming varicosities on muscle fibers. At this stage, Dip-AST 7-ir varicosities also are present on hindgut muscle precursor cells.

At $70 \%$ of development, Dip-AST 7-ir axons are seen in $\mathrm{N} 1$ of the thoracic ganglia in addition to $\mathrm{N} 3$ and N4. Individual axons that arborize into several branches to innervate more than one muscle can be distinguished clearly, suggesting common immunoreactive motor innervation. This is the case with muscles 90 and 93 (M90 and M93), which are innervated by branches of one immunoreactive axon leaving the mesothoracic ganglion through $\mathrm{N} 4$. Immunoreactive axons form varicosities on leg muscles,
N1B. Other immunoreactive axons leave the thoracic ganglia to innervate several muscles. Anterior is at the top, and the ventral midline is on the left. Scale bar $=100 \mu \mathrm{m}$.

prospective flight muscles, and other thoracic and abdominal skeletal muscles (Fig. 3). In the case of the dorsal longitudinal muscles M81 and M112, only the two most ventral fiber bundles show Dip-AST 7-ir varicosities. A single immunoreactive axon leaves the metathoracic ganglion through $\mathrm{N} 6$ to innervate the dorsal diaphragm. Longitudinal muscles of the rectum also receive immunoreactive innervation. Among several groups of Dip-AST-ir somata in the brain, one cluster is situated in the pars lateralis of the protocerebrum. Their axons run in the nervi corpori cardiaci to the corpora allata.

In embryos at $80 \%$ of development, muscles M60, M67, M81, M83, M84, M86, M87, M88, M90, M92, M93, M99, M112, M116, M119, M129, M135, and M139 receive DipAST 7-ir innervation (Table 1). In the abdomen, the dorsal and ventral diaphragm and some dorsoventral skeletal muscles also are targets of Dip-AST 7-ir innervation.

\section{Dip-AST-ir varicosities on muscles and peripheral nerves in adult locusts}

To confirm the persistence of Dip-AST 7-ir innervation of skeletal muscles in the adult, immunocytochemical stainings were carried out on wholemounts and on cryosections and paraffin sections of several muscles. In all muscles examined, Dip-AST 7-ir axon varicosities on the surface of muscle fibers were stained (Table 1, Fig. 4). Compared with the pattern of embryonic muscles, immunoreactive varicosities on adult muscles were more sparse and patchy in their distribution but were of similar size (1-5 $\mu \mathrm{m})$ and shape. 
TABLE 1. Diploptera-Allostatin Innervation of Embryonic and Adult Skeletal Muscles in the Thoracic Segments Through the Nerves in Which the Immunoreactive Axons Have Been Identified ${ }^{1}$

\begin{tabular}{lclcc}
\hline Muscle & Segment & \multicolumn{1}{c}{ Nerve } & Embryo & Adult \\
\hline M67 (ventral longitudinal) & T1 & N4C & + & + \\
M60 (ventral longitudinal) & T2 & N1A & + & + \\
M81 (dorsal longitudinal) & T2 & N1D1 & + & CLN \\
M83 (first tergosternal) & T2 & N3A1 & + & $?$ \\
M84 (second tergosternal) & T2 & N3A1 & + & $?$ \\
M86 (pleurosternal) & T2 & N4B3 & + & $?$ \\
M87 (ventral longitudinal) & T2 & N1RN & + & CLN \\
M88 (ventral longitudinal) & T2 & N1RN & + & CLN \\
M90 (remotor 1) & T2 & N4D1 & + & $?$ \\
M92 (anterior coxa rotator) & T2 & N3C1 & + & + \\
M93 (posterior coxa rotator) & T2 & N4C & + & + \\
M99 (subalar) & T2 & N4D3 & + & $?$ \\
M112 (dorsal longitudinal) & T3 & N1D1 & + & CLN \\
M116 (ventral longitudinal) & T3 & N1A & + & CLN \\
M119 (remotor 1) & T3 & N4D & + & $?$ \\
M129 (subalar) & T3 & N4D & + & $?$ \\
M135 (extensor tibiae) & T3 & N3C and N5B & + & $?$ \\
M139 (retractor unguis) & T3 & N5 & + & $?$ \\
\hline
\end{tabular}

${ }^{1} \mathrm{M}$, muscle; T1, prothoracic ganglion; T2, mesothoracicganglion; T3, metathoracic ganglion; N, nerve; CLN, common lateral neuron; +, somatic origin of the axon not determined; CLN, innervation through the CLN neuron; ?, muscles investigated only in embryos.
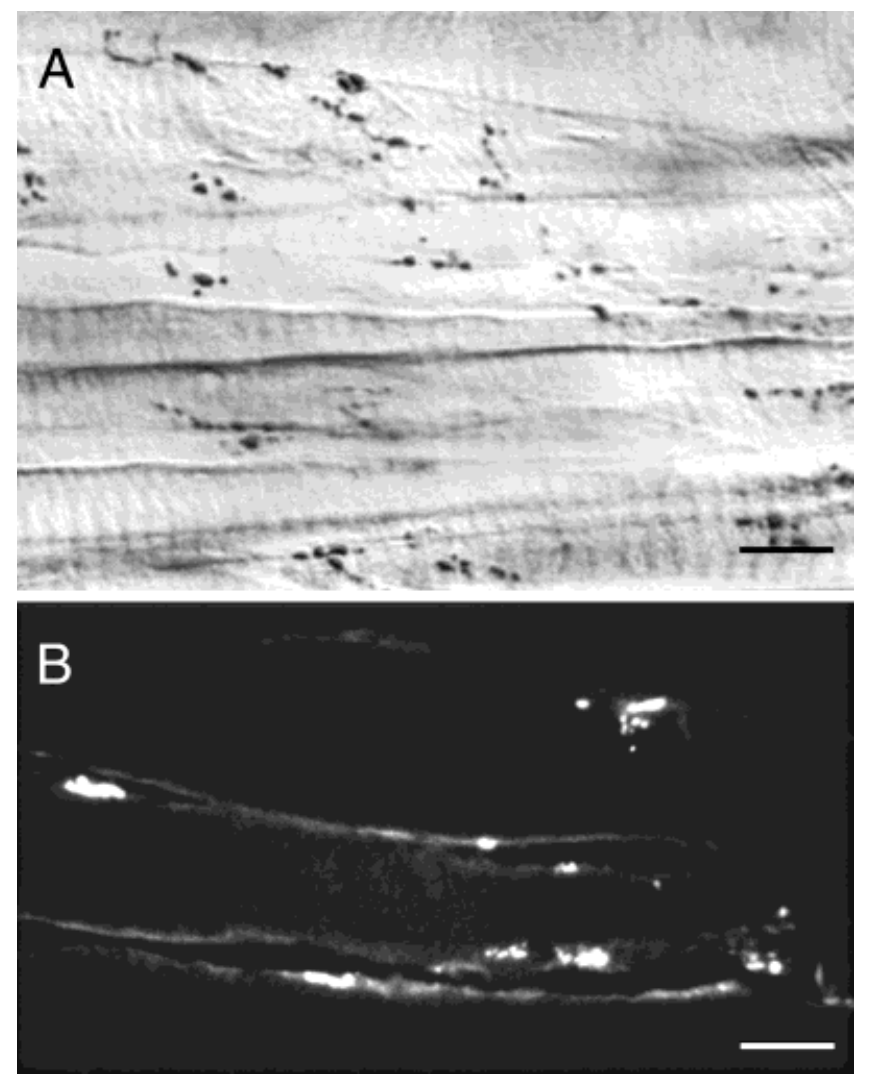

Fig. 4. Dip-AST 7-ir varicosities on thoracic muscles in the adult. A: Wholemount of M92. B: Immunofluorescent staining of a longitudinal cryosection $(12 \mu \mathrm{m})$ of M112. Scale bars $=50 \mu \mathrm{m}$ in A; $25 \mu \mathrm{m}$ in B.

In addition to Dip-AST 7-ir axons forming varicosities on skeletal muscle fibers, several immunoreactive branches form neurohaemal structures within the roots of N3 and N5 (Fig. 5A). Immunoreactive endings also are prominent in the nerve sheath of the median nerve of the metathoracic ganglion and around the junctions from metathoracic $\mathrm{N} 1$ to the recurrent neve of nerve $1(\mathrm{~N} 1 \mathrm{RN}), \mathrm{N} 1 \mathrm{~A}$, and N1B
(Figs. 5B,C, 11). The neurohaemal structures spread in the sheath for a distance of $\approx 150 \mu \mathrm{m}$ and end before the nerve branches contact their target muscles M87, M88, and M116. The size of these varicosities is similar to that of varicosities on the muscle fibers. On nerve 1 branch $D_{1}$ $\left(\mathrm{N}_{1} \mathrm{D}_{1}\right)$, Dip-AST 7-ir neurohaemal release sites were not observed.

\section{Dip-AST 7-ir neurons in the meso- and metathoracic ganglia}

In the meso- and metathoracic ganglia, several groups of Dip-AST 7-ir neurons with rather heterogeneous staining intensity are present bilaterally and medially in both the ventral part and the dorsal part. In addition to the immunoreactive cell bodies, there are numerous processes that ramify throughout the neuropil (Fig. 6). In the mesothoracic ganglion, $\approx 115$ neurons showed Dip-AST 7 immunoreactivity. In the metathoracic ganglion, which, in the locust, is fused with the neuromeres of the first three abdominal segments, $\approx 220$ immunoreactive neurons were counted (Fig. 7). The numbers were obtained from serial sections of three sets of ganglia. Several Dip-AST 7-ir axons extend into the connectives and single axons project into efferent nerves. In the metathoracic ganglion, axons of the Dip-AST 7-ir median cells exit the ganglion through the thoracic median nerves to form the neurohaemal varicosities along this nerve that are described above.

\section{Identification of a Dip-AST 7-ir common motor neuron}

To identify the cellular origin of the immunoreactive muscle innervation, double-labeling experiments were performed. Backfills from M112 stained the 5 metathoracic and 13 mesothoracic motor neurons described for this muscle in previous investigations (Kutsch and Heckmann, 1995; Steffens and Kutsch, 1995). In addition, an as yet undescribed neuron with five efferent axons was stained. The axons exit the CNS through nerves supplying muscles M81, M87, M88, and M116. In backfills from these muscles, the newly discovered neuron could be found consistently in a lateral position together with the set of known motor neurons for these muscles. Axon branches of this neuron also extend into the dorsal nerves of $\mathrm{A} 1, \mathrm{~A} 2$, and $\mathrm{A} 3$. The wide projection of this neuron indicates that it is a common motor neuron. Therefore, and because of its lateral position of the cell body in the ganglion, we term it the CLN. When backfills from M87, M112, and M116 were stained subsequently with the Dip-AST 7 antiserum, only this neuron was consistently double-labeled (Fig. 8, yellow neuron).

\section{Morphology of the common lateral motor neuron}

The soma of the CLN is located in the first abdominal neuromere of the fused metathoracic ganglion ipsilateral with respect to the target muscles. The position was verified in embryos, in which the different neuromeres forming the metathoracic ganglion are separated clearly (Fig. 9). Figure 10 shows the anatomy of the CLN and its axon branches in the adult. The soma has a diameter of 50 $\mu \mathrm{m}$. The primary neurite of the CLN extends ventrally toward the midline, where it gives rise to an ascending branch in the ventral median tract (nomenclature according to Tyrer and Gregory, 1982). The neurite subsequently 

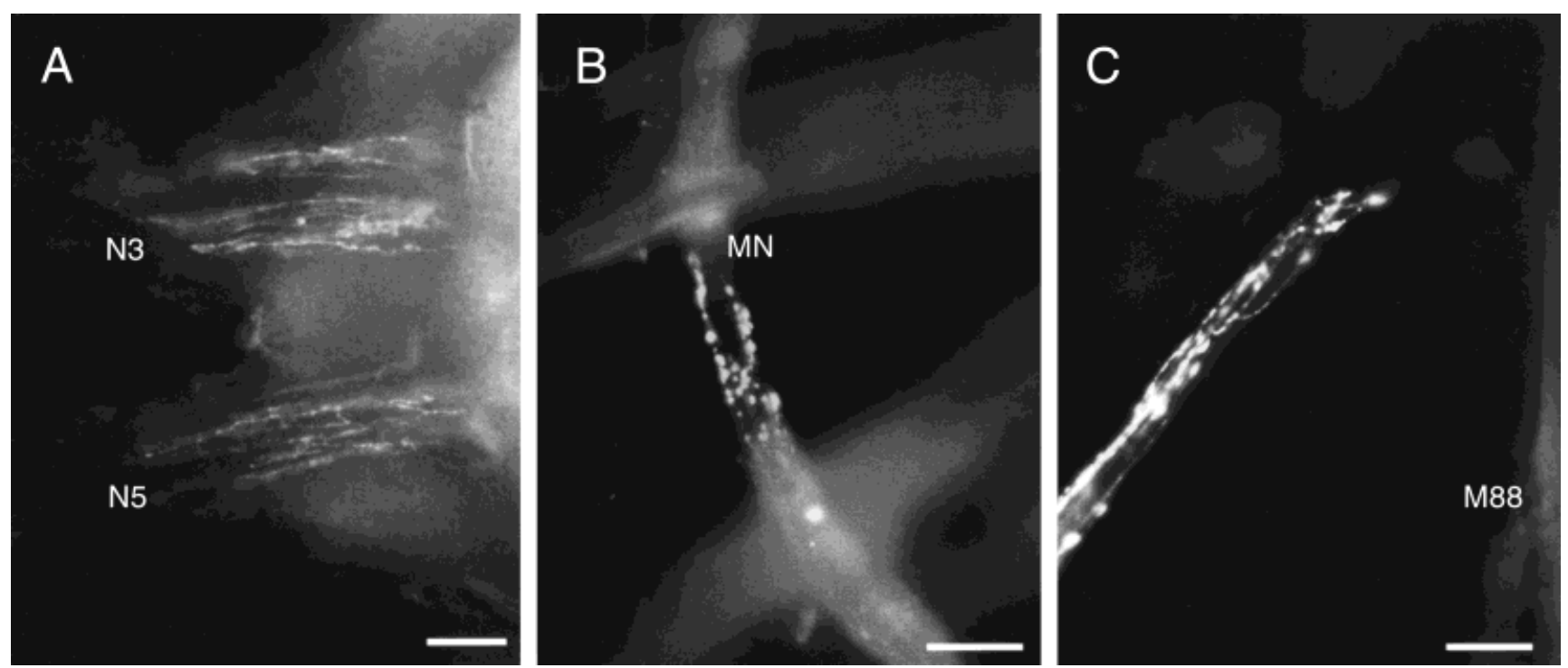

Fig. 5. Neurohaemal Dip-AST 7-ir varicose axons in nerve roots and on the surface of peripheral nerves. A: Immunoreactive axons terminate in the roots of N3 and N5 close to their exit of T2. Single immunoreactive axons projecting beyond the neurohaemal sites toward peripheral targets are not seen in this plane of focus. B: Dip-AST 7 -ir varicosities in a superficial position in the neurilemma of the
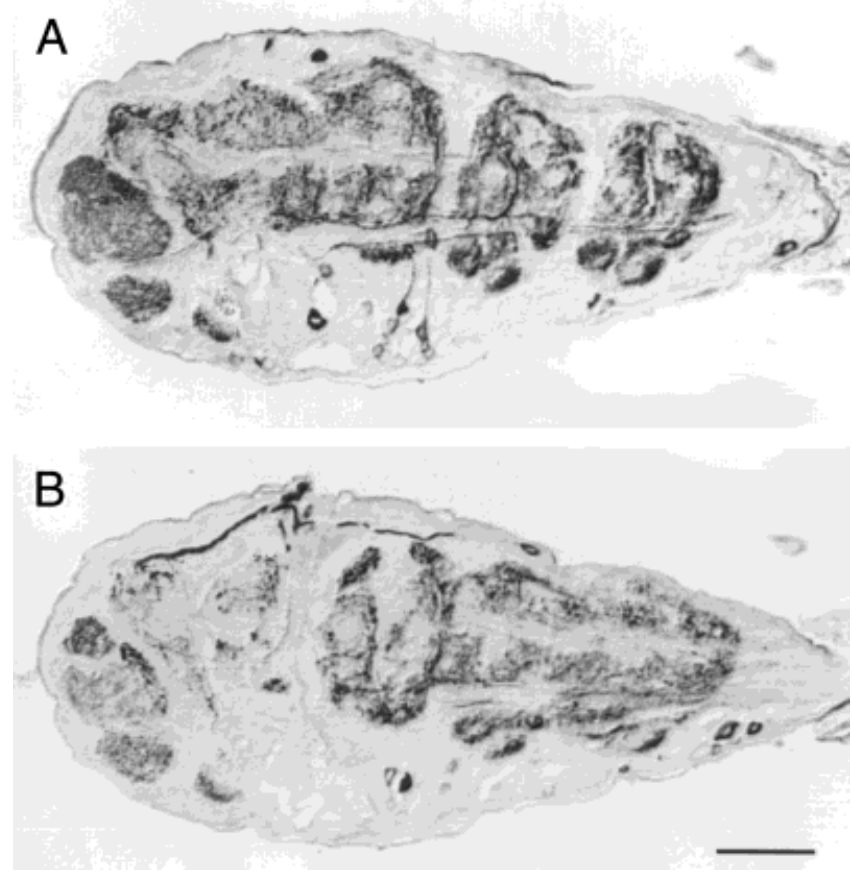

Fig. 6. A,B: Dip-AST 7 immunoreactivity in two consecutive, sagittal, paramedial sections of a paraffin-embedded metathoracic ganglion from an adult. Anterior is to the left. Scale bar $=200 \mu \mathrm{m}$.

loops dorsally through the T-tract, where it gives rise to a descending branch in the median dorsal tract. The neurite branches off a first efferent axon, which traverses the lateral neuropil and exits the ganglion through the dorsal nerve $(\mathrm{Ab} 3 \mathrm{DNV})$ of the third abdominal neuromere. The median nerve (MN) in the first abdominal neuromere. C: Dip-AST 7-ir varicosities on N1RN near its target, M88, in the metathoracic segment. The immunoreactive motor axon supplying the innervation of muscle fibers is not in the plane of focus. Anterior is at the top. Scale bars $=100 \mu \mathrm{m}$ in $\mathrm{A} ; 50 \mu \mathrm{m}$ in $\mathrm{B}, \mathrm{C}$.

neurite continues anteriorly in the median dorsal tract. At the turning point, it sends off a second efferent axon, which leaves the ganglion through the dorsal nerve (Ab2DNV) of the second abdominal neuromere. The neurite extends laterally in the median dorsal tract, where it gives rise to a third and a fourth efferent axon. The third axon exits the metathoracic ganglion through N6, which is a fused nerve of the dorsal nerve of the first abdominal neuromere and N6 of the third thoracic neuromere. The fourth axon leaves the ganglion through $\mathrm{N} 1$ of the metathoracic neuromere. The fifth efferent axon enters the anterior connective and extends into the mesothoracic ganglion, where it projects through N1 to the periphery.

The peripheral branching pattern and targets of the CLN in the meta- and mesothoracic segment are summarized schematically in Figure 11. The results were determined with backfills and could be confirmed with Dip-AST 7 immunolabeling. The CLN forms Dip-AST 7-ir varicosities in the nerve sheath around the junctions from the metathoracic $\mathrm{N} 1$ to N1RN, N1A, and N1B. The fine axon leaving the metathoracic ganglion through $\mathrm{N} 1$ divides along its way within N1 to supply at least four muscles. One branch enters N1RN and supplies the muscles M87 and M88. Another branch enters N1 and supplies M116 through N1A and M112 through $\mathrm{N}_{1} \mathrm{D}_{1}$. The target of a branch in N1B was not identified. We never detected an immunoreactive axon in N1C. The immunoreactive axon seems to terminate at $\mathrm{N}_{1} \mathrm{D}_{1}$, where it innervates selectively two ventral fiber bundles of the dorsal longitudinal flight muscle M112. The axon of the CLN leaving the mesothoracic ganglion through $\mathrm{N} 1$ innervates M81. It is likely that N1A in the mesothoracic segment also contains a branch of the CLN, because this was seen in embryos. However, the anatomical situation in the adult prevents confirmation by backfills and immunostaining. 

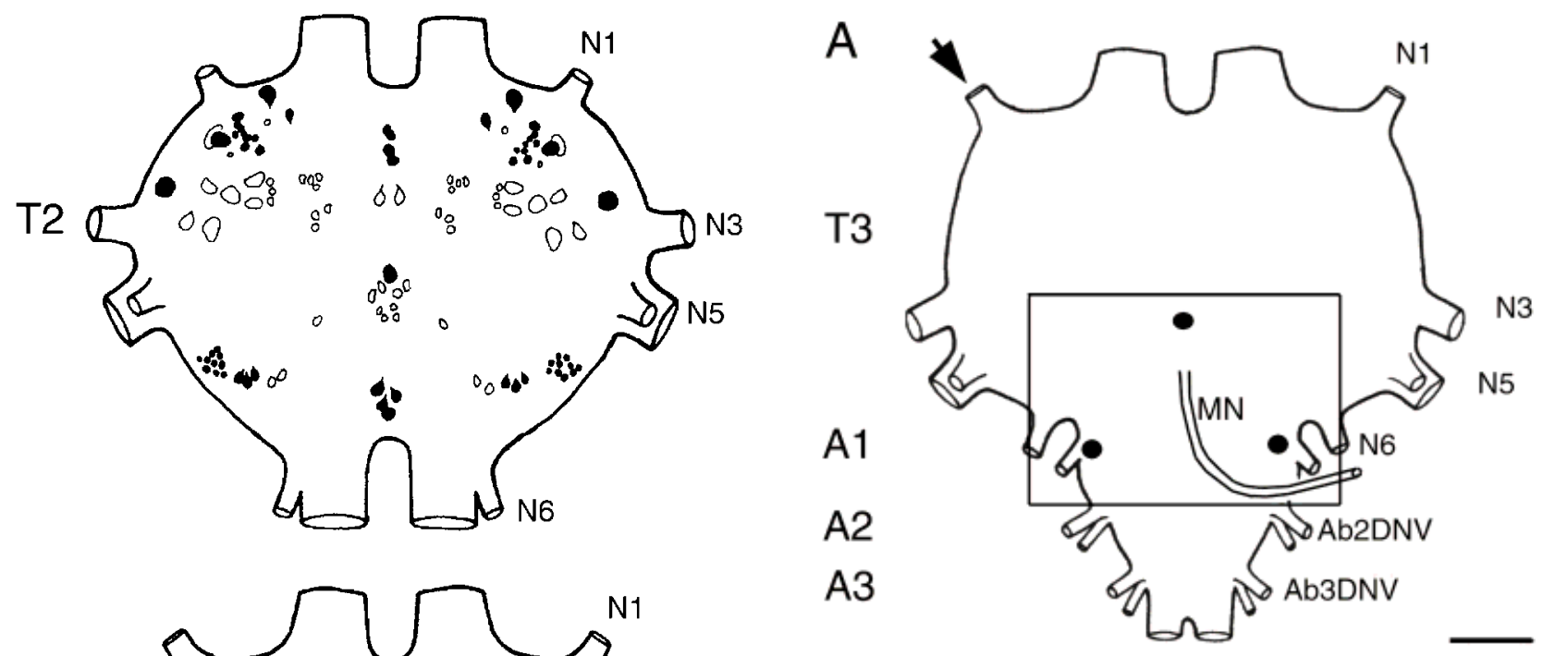

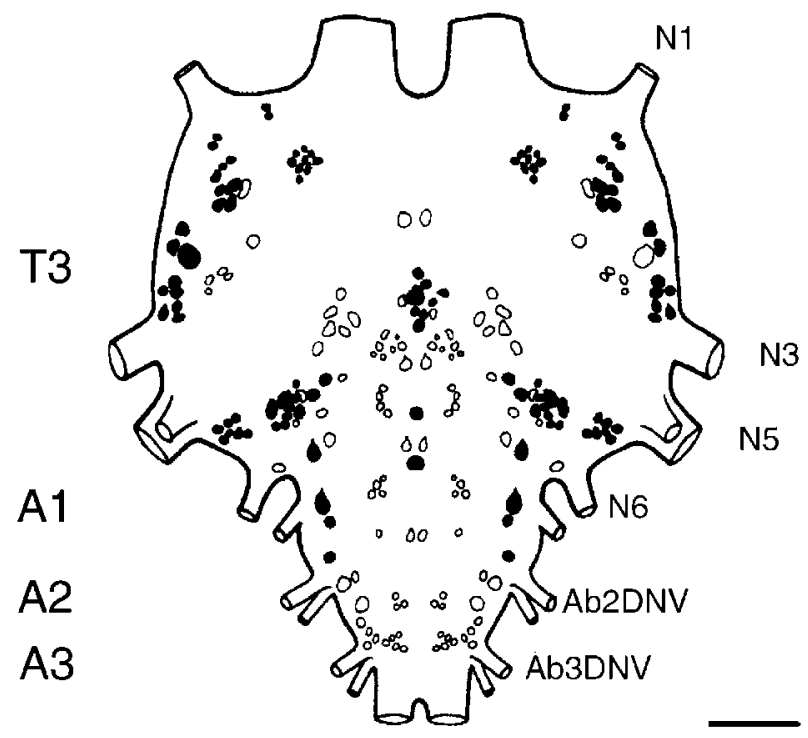

Fig. 7. Dip-AST 7-ir neurons in the meso- and metathoracic ganglion. Camera lucida drawing. Neurons lying dorsal to the exit plane of N5 are shaded, and neurons ventral to it are clear. Anterior is to the top. Ab2DNV and Ab3DNV, dorsal nerves of abdominal neuromeres 2 and 3 , respectively. Scale bar $=200 \mu \mathrm{m}$.

\section{DISCUSSION \\ Development of Dip-AST 7 immunoreactivity}

We have shown that, in the migratory locust, Dip-AST 7 -ir neurons are detected as early as $43 \%$ of embryonic development, and immunoreactive varicosities are present on muscle precursor cells as early as $55 \%$ of development. An early occurrence of the modulatory substances myomodulin, proctolin, and serotonin in the developing nervous system of locusts also was shown. Myomodulin is detectable in embryos first at $50 \%$ of development, and the complete adult pattern of neuronal staining is present at 85-90\% of development (Swales and Evans, 1994). The acquisition of proctolin immunoreactivity begins at $50 \%$ of embryonic development (Keshishian and O'Shea, 1985b). Serotonin immunoreactivity in locust embryos is detectable first between 54\% and 56\% of development (Taghert and Goodman, 1984). Thus, allatostatin is one of the

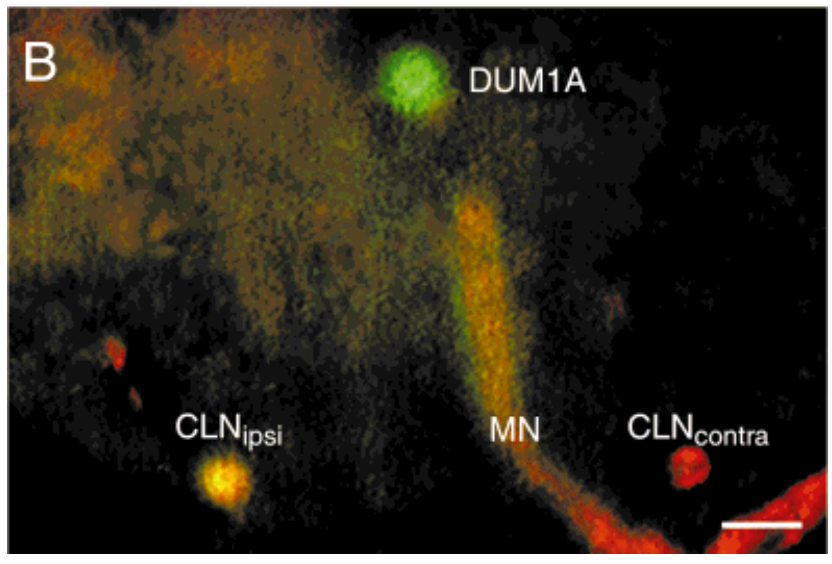

Fig. 8. Double labeling of the common motor neuron (CLN). Neurons projecting into N1 of T3 were backfilled unilaterally (A, arrow) with Lucifer yellow. Dip-AST 7 immunoreactivity was visualized with indirect immunofluorescence by using an indocarbocyanin (Cy-3)-conjugated secondary antibody (red). A: Schematic representation of T3 indicating the area shown in B. For abbreviations, see Figure 6. B: Superposition of two digital images showing the backfilled dorsal unpaired median 1A (DUM1A) neuron (green); the contralateral, immunoreactive neuron (CLNcontra) and two small, ipsilateral Dip-AST 7-ir neurons in the same plane of focus (red); and the double-labeled ipsilateral CLN neuron (CLNipsi; yellow). Other motor neurons of M112, backfilled through N1, and additional immunoreactive neurons are not in the plane of focus. The median nerve (MN) contains immunoreactive, varicose axons originating from median somata. Scale bars $=200 \mu \mathrm{m}$ in A; $100 \mu \mathrm{m}$ in B.

earliest detectable neuromodulators in the nervous system of developing locusts.

The numbers of immunoreactive somata present in the meso- and metathoracic ganglia of adult $L$. migratoria, $\approx$ 115 and $\approx 220$, far exceed the numbers of allatostatinimmunoreactive neurons reported in an earlier study (Veelaert et al., 1995) in which, in both L. migratoria and Schistocerca gregaria, only 16 neurons and 27 neurons were stained in the meso- and metathoracic ganglia with an antiserum raised against Dip-AST 2 (nomenclature according to Gäde et al., 1997). For this isoform, several different names have been used: ASB2 (Pratt et al., 1991); 


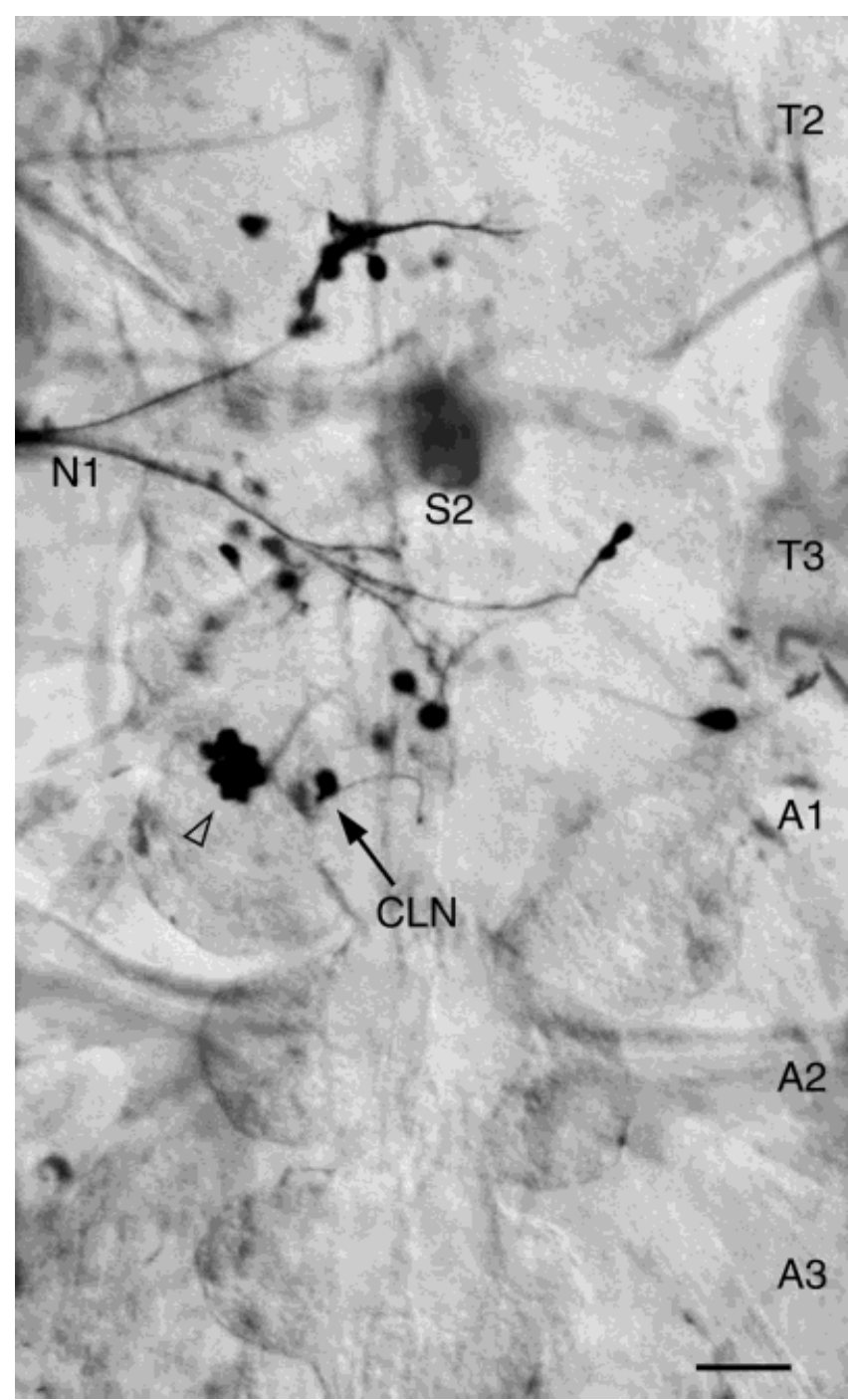

Fig. 9. Retrograde labeling of the CLN in A1 of an embryo at $70 \%$ of development. The cell body (arrow) is located in the first abdominal neuromere (A1) of T3. Compared with backfills in the adult, some supernumerous cells (arrowhead) were labeled by retrograde filling of neurons projecting through N1. S2, posterior spina. Scale bar = $35 \mu \mathrm{m}$.

AST 5, Dip-AST 5, or dipstatin-2 (Veelaert et al., 1995), and B2 (Vitzthum et al., 1996). Dip-AST 2 and Dip-AST 7 share a similar $\mathrm{COOH}$-terminal amidated sequence ending in YNFGL- $\mathrm{NH}_{2}$ and YGFGL- $\mathrm{NH}_{2}$, respectively, but there is no homology in the N-terminal region of the two isoforms. The difference in numbers of somata stained with the Dip-AST 2 and Dip-AST 7 antisera likely is due to their different specificity. They may stain different populations of neurons that contain different allatostatin isoforms. Although the antiserum against Dip-AST 7 was shown to be nearly 2 orders of magnitude more sensitive to Dip-AST 7 than to other isoforms, including Dip-AST 2 (Vitzthum et al., 1996), neurons containing these other isoforms also may be stained, accounting for the higher numbers of immunoreactive somata found in the current study.

\section{CLN represents a new type of common neuron}

Motor neurons generally are specific for only one target muscle. In arthropods, however, a few cases are known in which individual excitatory, inhibitory, or modulatory neurons supply several muscles that, therefore, are termed common neurons. We consider modulatory neurons functionally as motor neurons when they supply muscles by efferent axons, which form release sites on muscle fibers (see also O'Shea, 1985). Common excitatory innervation is rare. In the cockroach, some coxal muscles receive common excitatory input through the slow coxal depressor motor neuron, which also releases the peptide proctolin (Adams and O'Shea, 1983; Stokes, 1987). In decapod crustaceans, common excitatory innervation is present for the stretcher and opener muscles in the walking legs and results in coactivation of the two muscles. In this system, uncoupling from common excitatory input is achieved by two inhibitory neurons specific for each muscle (Wiens and Rathmayer, 1985). A common excitatory neuron is also described for the larval deep abdominal flexor muscles in natantian (tailed) decapod crustaceans (Stephens and Govind, 1981).

Common inhibitory (CI) neurons occur throughout thoracic and abdominal ganglia in insects and crustaceans. In locusts, $\mathrm{CI}_{1-3}$ of the thoracic ganglia are particularly well studied (Pearson and Bergman, 1968; Burrows, 1973; Hale and Burrows, 1985; Watson et al., 1985). $\mathrm{CI}_{1}$, depending on the segment, innervates 12-13 ipsilateral muscles that are involved in moving the proximal leg joints. The other two, $\mathrm{CI}_{2}$ and $\mathrm{CI}_{3}$, both innervate an identical set of four muscles in the distal part of the leg (Hale and Burrows, 1985). In decapod crustaceans, a single common inhibitory neuron $\left(\mathrm{CI}_{1}\right)$ innervates all extrinsic and intrinsic muscles of a walking leg (Rathmayer and Bevengut, 1986; Bevengut and Cournil, 1990). The targets of common inhibitors are located exclusively on one side of the body and are confined to one segment.

The third group of common motor neurons is the efferent population of modulatory dorsal unpaired median (DUM) neurons in insects (Hoyle, 1978; Watson, 1984; Campbell et al., 1995). They occur throughout the ganglionic chain and possess octopamine as a modulatory transmitter (Evans and O'Shea, 1977; Stevenson et al., 1992; Bräunig et al., 1994, Bräunig, 1997). The characteristic morphology of the DUM neurons is the median position of their somata and the bifurcation of their primary neurites. They innervate several targets restricted to one segment but located symmetrically on both sides of the animal.

Another common neuron of unknown function with efferent axons projecting through N1, N3, and N6 of the mesothoracic ganglion was described by Siegler and Pousman (1990). However, only one target muscle of this neuron (C1, 3, 6), M112, has been identified so far (Steffens and Kutsch, 1995).

The Dip-AST 7-ir CLN found in this study represents a new type of common neuron. It is a multisegmental neuron that has efferent axons leaving from five neuromeres through homologous nerves for their peripheral targets in five segments. These targets are restricted to one body half. Recently, Bräunig (1999) has described a Dip-AST 7-ir neuron in the first abdominal neuromere of the metathoracic ganglion of the locust that sends axons into 


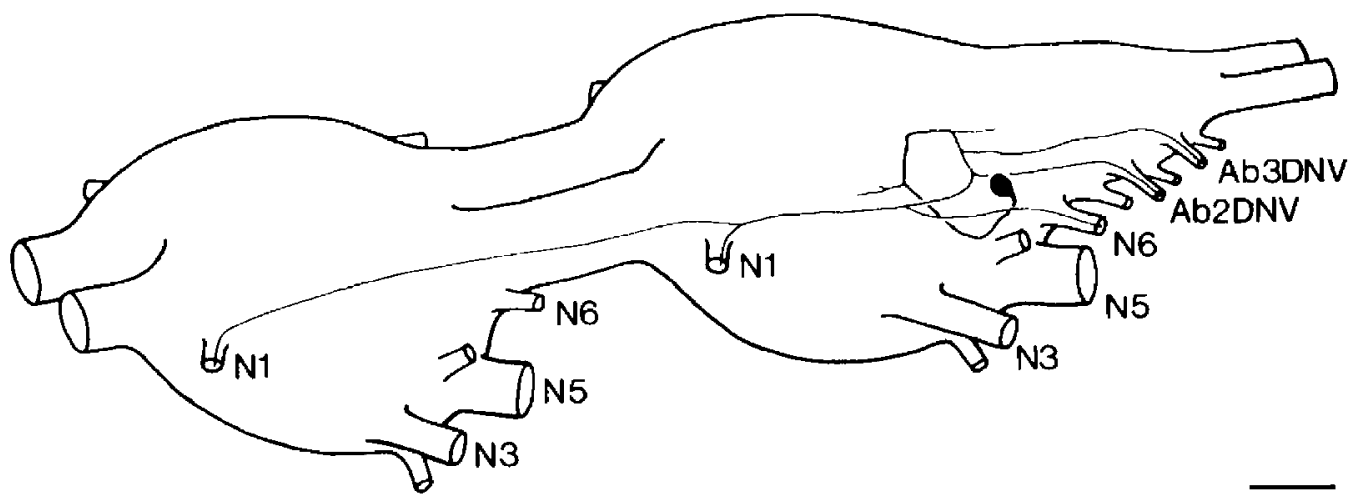

Fig. 10. Three-dimensional drawing of the course of the neurites of the CLN in the meta- and mesothoracic ganglion. The primary neurite loops from the ventral side to follow the T-tract to the dorsal side of the ganglion before giving off axons that leave the ganglion through $\mathrm{N} 1$ of T2, N1 of T3, and their homologs in A1 to A3. Scale bar $=200 \mu \mathrm{m}$.
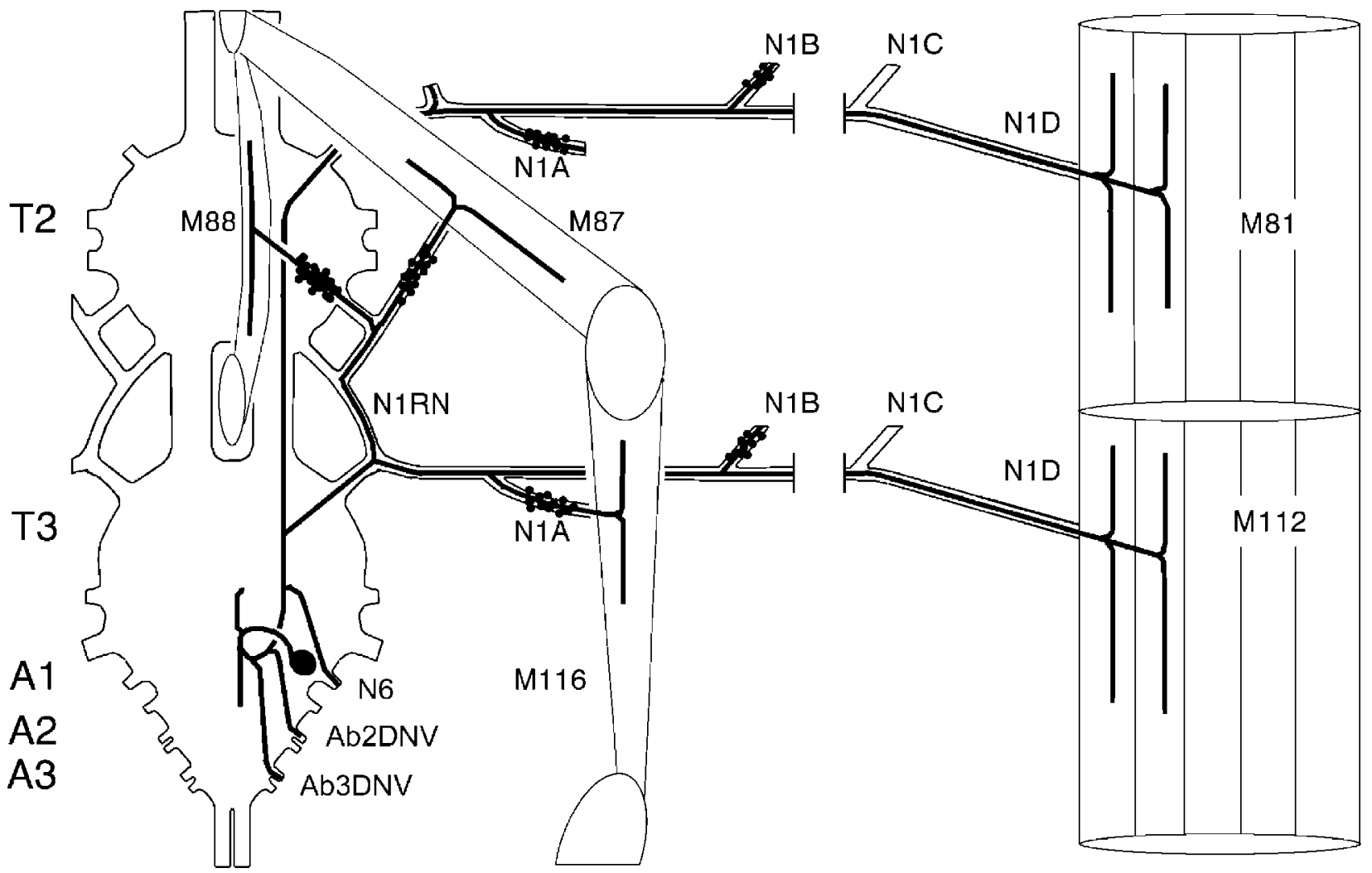

Fig. 11. Schematic representation of the CLN with identified targets and putative neurohaemal release sites (dots) in the thorax.

the dorsal nerves innervating the heart and alary muscles. This neuron is likely to be identical to the CLN, although its branches, which extend anteriorly into the meta- and mesothoracic N1 and supply thoracic skeletal muscles, were not described by Bräunig. In some aspects, the peripheral branching pattern of the CLN resembles the branching patterns of the metathoracic bilaterally projecting DUM1A and DUM1B neurons, which supply ventral and dorsal muscles, respectively (Bräunig et al., 1994). However, the axon of the CLN could be distinguished clearly in our study from that of the DUM1B neuron in the metathoracic ganglion, which exits through N1 and branches into N1RN, N1A, and N1B (Bräunig et al., 1994). In backfills from M88, two different axons were traced in N1RN. They gave rise to branches extending into N1A and $\mathrm{N} 1 \mathrm{~B}$. One was the axon of DUM1B, and the second was that of the CLN. Only one axon extended into N1D, supplying the dorsal longitudinal muscles: this was the Dip-AST 7-ir axon of the CLN. In backfills from M112, the axon of the CLN was distinguished clearly from that of 
DUM1A (also known as DUMDL; Hoyle 1978) by its branch projecting into N1B.

Among the muscles innervated by the CLN are the mesothoracic muscles M87 and M88, which, together with M60, move the mesothorax relative to the prothorax. The function of M116, together with M117, is to brace the pull of the mesothoracic ventral longitudinal muscles on the sternal plates of the prothorax (Snodgrass, 1929). Thus, all five of these muscles are responsible for the position of thoracic segments relative to one another on one side of the body.

The activity of muscles located in several segments is controlled by their specific motor neurons located in the ganglia of the corresponding segments. For the coordination of groups of skeletal muscles within a segment and across adjacent segments, either interneurons become involved, which regulate the activation of the specific segmental motor neurons, or common efferent neurons modulate the efficiency of these motor neurons at their peripheral targets. Common inhibitory neurons control unilateral targets restricted to one segment. DUMneurons modulate bilateral targets, which also are restricted to one segment. The anatomy of the CLN suggests that it can provide a cooperative modulation of the performance of a set of muscles on one side of the body in several segments.

\section{CLN may be complemented by other Dip-AST 7-ir common modulatory motor neurons}

In addition to Dip-AST-ir innervation of the muscles provided by the CLN, we found immunoreactive varicosities on other skeletal muscles in the meso- and metathoracic segment in the locust, suggesting a much wider efferent innervation through Dip-AST 7-ir motor neurons. For these muscles, the cellular origin of the Dip-AST 7-ir innervation obviously is located in the CNS but was not identified. The results obtained in the embryo suggest that the immunoreactive innervation of at least some of these muscles also is provided by common neurons. The fact that, at $50 \%$ and $70 \%$ of development, single immunoreactive axons divide into branches that supply several leg and thoracic muscles suggests this common innervation. In adults, M90, M99, M119, and M129 all are innervated by branches of N4D. In N4D of the meso- and the metathoracic segment, only a single Dip-AST 7-ir axon was detected in embryos, again suggesting modulatory innervation of these muscles by a common neuron that, nonetheless, is not homologous to the CLN. Because the numbers of stained axons in the nerves leaving the thoracic ganglia are small, the proportion of motor neurons among the stained neurons is less than $10 \%$.

\section{Targeted and distributed action of allatostatin}

Most modulatory peptides with peripheral targets are synthesized by neurons in the CNS. They are released either directly on muscle fibers from neuromuscular junctions or at neurohaemal sites from which they are distributed at relatively low concentrations through the haemolymph. The most prominent neurohaemal organs are along the median nerve of the metathoracic ganglion and in the neural sheaths of other peripheral nerves (Brady and Maddrell, 1967; Raabe, 1983; Swales and Evans, 1994; Helle et al., 1995; Bräunig, 1997). Individual DUM neurons and the CLN form both neurohaemal sites associated with peripheral nerves and varicosities on target muscles. Thus, single neurons provide the anatomical basis for both distributed action and targeted action.

In dorsal longitudinal muscles M81 and M112, Dip-AST 7-ir varicose endings of the CLN are restricted to only two bundles of fibers. A similar selectivity is prominent in the crustacean Idotea, in which only two to four fibers within the five to eight fibers of each dorsal extensor muscle receive Dip-AST 7-ir innervation (Kreissl et al., 1999). Selective distribution of peptidergic innervation within muscles also has been found for proctolin in the extensor tibiae of the locust and in Drosophila (O'Shea and Bishop, 1982; Anderson et al., 1988).

We do not yet know the physiological effects of allatostatin on skeletal muscles in insects. We showed that allatostatin inhibits neuromuscular performance in two isopod crustaceans and in the crab Eriphia spinifrons (Kreissl et al., 1999). This inhibition is effected by way of complementary pre- and postsynaptic mechanisms: a reduction of evoked transmitter release at neuromuscular junctions and a reduction of the contraction amplitude of current-clamped muscle fibers. The effects are present regardless of whether or not an individual muscle fiber or the muscle as a whole receives Dip-AST 7 innervation. It is assumed that, for muscles that lack peptidergic innervation, neurohaemal organs are the source of allatostatin that allows modulation of distributed targets (Kreissl et al., 1999). The numerous Dip-AST 7-ir neurohaemal organs found in the locust may be the morphologic correlates for the down-regulation of the responses of a number of targets. Knowing the anatomy of one Dip-AST 7-ir motor neuron and a number of its target muscles now permits a detailed analysis of the effects of the activity of this neuron and the mechanisms involved in this type of modulation in insects.

\section{ACKNOWLEDGMENTS}

We thank Birgit Rapp for assistance at various stages of the work and Mary A. Cahill for help with the English.

\section{LITERATURE CITED}

Adams ME, O'Shea M. 1983. Peptide cotransmitter at a neuromuscular junction. Science 221:286-289.

Albrecht FO. 1953. The Anatomy of the migratory locust. London: Athlone Press.

Anderson MD, Halpern M, Keshishian H. 1988. Identification of the neuropeptide transmitter proctolin in Drosophila larvae: characterization of muscle fiber-specific neuromuscular endings. J Neurosci 8:242255.

Baines RA, Lange AB, Downer RGH. 1990. Proctolin in the innervation of the locust mandibular closer muscle modulates contractions through the elevation of inositol trisphosphate. J Comp Neurol 297:479-486.

Bartos M, Allgäuer C, Eckert M, Honegger HW. 1994. The antennal motor system of crickets: proctolin in slow and fast motor neurons as revealed by double labeling. Eur J Neurosci 6:825-836.

Bendena WG, Garside CS, Yu CG, Tobe SS. 1997. Allatostatins: diversity in structure and function of an insect neuropeptide family. Ann NY Acad Sci 814:53-66.

Bentley D, Keshishian H, Shankland M, Toroian-Raymond A. 1979. Quantitative staging of embryonic development of the grasshopper, Schistocerca nitens. J Embryol Exp Morphol 54:47-74.

Bevengut M, Cournil I. 1990. Gamma-aminobutyric acid-inhibitory motor innervation of leg muscles of the shore crab. Eur J Neurosci 2:132-139.

Bishop CA, Wine JJ, O'Shea M. 1984. Neuropeptide proctolin in postural motoneurons of the crayfish. J Neurosci 4:2001-2009.

Bishop CA, Wine JJ, Nagy F, O'Shea M. 1987. Physiological consequences of 
a peptide cotransmitter in a crayfish nerve-muscle preparation. J Neurosci 7:1769-1779.

Brady J, Maddrell SHP. 1967. Neurohaemal organs in the medial nervous system of insects. Z Zellforsch 76:389-404.

Bräunig P. 1997. The peripheral branching pattern of identified dorsal unpaired median (DUM) neurons of the locust. Cell Tissue Res 290:641654.

Bräunig P. 1999. The structure of identified neurons innervating the lateral cardiac nerve cords in migratory locusts. Int J Insect Morphol Embryol 28:81-89.

Bräunig P, Stevenson PA, Evans PD. 1994. A locust octopamine-immunoreactive dorsal unpaired median neuron forming terminal networks on sympathetic nerves. J Exp Biol 192:225-238.

Breidbach O, Kutsch W. 1990. Structural homology of identified motor neurons in larval and adult stages of hemi-and holometabolous insects. J Comp Neurol 297:392-409.

Burrows M. 1973. Physiological and morphological properties of the metathoracic common inhibitory neuron of the locust. J Comp Physiol 82:59-78.

Campbell HR, Thompson KJ, Siegler MVS. 1995. Neurons of the median neuroblast lineage of the grasshopper: a population study of the efferent DUM neurons. J Comp Neurol 358:541-551.

Campbell JI. 1961. The anatomy of the nervous system of the metathorax of Locusta migratoria migratorioides R \& F. Proc Zool Soc London 137:403-432.

Cook BJ, Holman GM. 1985. The role of proctolin and glutamate in the excitation-contraction coupling of insect visceral muscle. Comp Biochem Physiol 80C:65-73.

Davis NT, Veenstra JA, Feyereisen R, Hildebrand JG. 1997. Allatostatinlike-immunoreactive neurons of the tobacco hornworm, Manduca sexta, and isolation and identification of a new neuropeptide related to cockroach allatostatins. J Comp Neurol 385:265-284.

Duve H, Johnsen AH, Maestro JL, Scott AG, Jaros PP, Thorpe A. 1997. Isolation and identification of multiple neuropeptides of the allatostatin superfamily in the shore crab Carcinus maenas. Eur J Biochem 250:727-734.

Elia AJ, Orchard I. 1995. Peptidergic innervation of leg muscles of the cockroach, Periplaneta americana (L.), and a possible role in modulation of muscle contraction. J Comp Physiol A 176:425-435.

Elia AJ, TeBrugge VA, Orchard I. 1993. The pulsatile appearance of FMRFamide related peptides in the haemolymph and loss of FMRFamide-like immunoreactivity from neurohaemal areas of Rhodnius prolixus following a blood meal. J Insect Physiol 39:459-469.

Erxleben CFJ, deSantis A, Rathmayer W. 1995. Effects of proctolin on contractions, membrane resistance, and non-voltage dependent sarcolemmal ion channels in crustacean muscle fibers. J Neurosci 15:43564369.

Evans PD. 1984. Studies on the mode of action of octopamine, 5-hydroxytryptamine and proctolin on the myogenic rhythm in the locust. J Exp Biol 110:231-251.

Evans PD. 1994. The effects of myomodulin and structurally related neuropeptides on skeletal neuromuscular transmission in the locust. J Exp Biol 190:253-264.

Evans PD, Myers CM. 1986a. Peptidergic and aminergic modulation of insect skeletal muscle. J Exp Biol 124:143-176.

Evans PD, Myers CM. 1986b. The modulatory actions of FMRFamide and related peptides on locust skeletal muscle. J Exp Biol 126:403-422.

Evans PD, O'Shea M. 1977. An octopaminergic neuron modulates neuromuscular transmission in the locust. Nature 270:257-259.

Evans PD, Robb S, Cuthbert BA. 1989. Insect neuropeptides-identification, establishment of functional roles and novel target sites for pesticides. Pest Sci 25:71-83.

Facciponte G, Miksys S, Lange AB. 1995. The association of proctolin with a ventral abdominal muscle of Locusta migratoria. J Comp Physiol A 178:269-278.

Gäde G, Hoffmann KH, Spring J. 1997. Hormonal regulation in insects: facts, gaps, and future directions. Physiol Rev 77:963-1032.

Hale JP, Burrows M. 1985. Innervation patterns of inhibitory motor neurons in the locust. J Exp Biol 117:401-413.

Helle J, Dircksen H, Eckert M, Nässel DR, Spörhase-Eichmann U, Schürmann FW. 1995. Putative neurohemal areas in the peripheral nervous system of an insect, Gryllus bimaculatus, revealed by immunocytochemistry. Cell Tissue Res 281:43-61.

Hewes RS, Snowdeal EC III, Saitoe M, Taghert PD. 1998. Functional redundancy of FMRFamide-related peptides at the Drosophila larval neuromuscular junction. J Neurosci 18:7138-7151.

Hoyle G. 1978. The dorsal, unpaired, median neurons of the metathoracic ganglion. J Neurobiol 9:43-57.

Jorge-Rivera JC, Marder E. 1997. Allatostatin decreases stomatogastric neuromuscular transmission in the crab. J Exp Biol 200:2937-2946.

Keshishian H, O'Shea M. 1985a. The distribution of a peptide neurotransmitter in the postembryonic grasshopper central nervous system. J Neurosci 5:992-1004.

Keshishian H, O'Shea M. 1985b. The acquisition and expression of a peptidergic phenotype in the grasshopper embryo. J Neurosci 5:10051015.

Kreissl S, Uber A, Rathmayer W. 1995. Embryonic development of allatostatin-like immunoreactivity in neuromuscular systems of Locusta migratoria. In: Elsner N, Menzel R, editors. Proceedings of the 23rd Göttingen Neurobiology Conference. Stuttgart: G Thieme. p 205.

Kreissl S, Weiss T, Djokaj S, Balezina O, Rathmayer W. 1999. Allatostatin modulates skeletal muscle performance in crustaceans through preand postsynaptic effects. Eur J Neurosci 11:2519-2530.

Kutsch W, Heckmann R. 1995. Motor supply of the dorsal longitudinal muscles, I: homonomy and ontogeny of the motor neurons in locusts (Insecta, Califera). Zoomorphology 115:179-195.

Kutsch W, Schneider H. 1987. Histological characterization of neurons innervating functional different muscles of Locusta. J Comp Neurol 261:515-528.

Lange AB, Chan KK, Stay B. 1993. Effect of allatostatin and proctolin on antennal pulsatile organ and hindgut muscle in the cockroach, Diploptera punctata. Arch Insect Biochem Physiol 24:79-92.

Lange AB, Peef NM, Orchard I. 1994. Isolation, sequence and bioactivity of FMRFamide-related peptides from the central nerve cord. Peptides 15:1089-1094.

Lange AB, Bendena WG, Tobe SS. 1995. The effect of the thirteen Dip-allatostatins on myogenic and induced contractions of the cockroach (Diploptera punctata) hindgut. J Insect Physiol 41:581-588.

Mangerich S, Keller R. 1988. Localization of pigment-dispersing hormone $(\mathrm{PDH})$ immunoreactivity in the central nervous system of Carcinus maenas and Orconectes limosus (Crustacea) with reference to FMR Famide immunoreactivity in O. limosus. Cell Tissue Res 253:199-208.

Masler EP, Kelly TJ, Menn JJ. 1993. Insect neuropeptides: discovery and application in insect management. Arch Insect Biochem Physiol 22:87111.

May TE, Brown BE, Clements AN. 1979. Experimental studies upon a bundle of tonic fibers in the locust extensor tibialis muscle. J Insect Physiol 25:169-181.

Miao Y, Waters EM, Witten JL. 1998. Developmental and regional-specific expression of FLRFamide peptides in the tobacco hornworm, Manduca sexta, suggests functions at ecdysis. J Neurobiol 37:469-485.

Miksys S, Lange AB, Orchard I, Wong V. 1997. Localization and neurohemal release of FMRFamide-related peptides in the stick insect Carausius morosus. Peptides 18:27-40.

Myers CM, Evans PD. 1985. The distribution of bovine pancreatic polypeptide/FMRFamide-like immunoreactivity in the ventral nervous system of the locust. J Comp Neurol 234:71-73.

Nässel DR. 1996a. Neuropeptides, amines and amino acids in an elementary insect ganglion: functional and chemical anatomy of the unfused abdominal ganglion. Progr Neurobiol 48:325-420.

Nässel DR. 1996b. Peptidergic neurohormonal control systems in invertebrates. Curr Opin Neurobiol 6:842-850.

O'Shea M. 1985. Are skeletal motoneurons in arthropods peptidergic? In: Selverston AI, editor. Model neural networks and behavior. New York: Plenum Press. p 401-413.

O'Shea M, Adams MA. 1986. Proctolin: from "gut factor" to model neuropeptide. Adv Insect Physiol 19:1-28.

O'Shea M, Bishop CA. 1982. Neuropeptide proctolin associated with an identified skeletal motor neuron. J Neurosci 2:1242-1251.

Orchard I, Belanger JH, Lange AB. 1989. Proctolin: a review with emphasis on insects. J Neurobiol 20:470-496.

Pearson KG, Bergman SJ. 1968. Common inhibitory motor neurons in insects. J Exp Biol 50:445-471.

Penzlin H. 1989. Neuropeptides-occurrence and functions in insects. Naturwissenschaften 76:234-252.

Piek T, Mantel P. 1977. Myogenic contractions in locust muscle induced by proctolin and by wasp, Philanthus triangulum venom. J Insect Physiol 23:321-362

Pratt GE, Farnsworth DE, Siegel NR, Fok KF, Feyereisen R. 1989 
Identification of an allatostatin from an adult Diploptera punctata. Biochem Biophys Res Commun 163:1243-1247.

Pratt GE, Farnsworth DE, Fok KF, Siegel NR, McCormack AL, Shabanowitz J, Hunt DF, Feyereisen R. 1991. Identity of a second type of allatostatin from cockroach brains: an octodecapeptide amide with tyrosine-rich address sequence. Proc Natl Acad Sci USA 88:2412-2418.

Raabe M. 1983. The neurosecretory-neurohaemal system of insects; anatomical, structural and physiological data. Adv Insect Physiol 17:202-203.

Rathmayer W, Bevengut M. 1986. The common inhibitory neuron innervates every leg muscle in crabs. J Comp Physiol 158:665-668.

Rheuben MB. 1995. Specific associations of neurosecretory or neuromodulatory axons with insect skeletal muscles. Am Zool 35:566-577.

Robb S, Evans PD. 1990. FMRFamide-like peptides in the locust: distribution, partial characterization, and bioactivity. J Exp Biol 149:335-360.

Robb S, Packman LC, Evans PD. 1989. Isolation, primary structure and bioactivity of SchistoFLRFamide, a FMRFamide-like neuropeptide from the locust, Schistocerca gregaria. Biochem Biophys Res Commun 160:850-856.

Schiebe M, Orchard I, Watts R, Lange AB, Atwood HL. 1990. Characterization and partial purification of different factors with contractionpotentiating activities from neurohaemal organs in the locust. J Comp Neurol 291:305-312.

Schneider LE, Sun ET, Garland DJ, Taghert PH. 1993. An immunocytochemical study of the FMRFamide neuropeptide gene products in Drosophila. J Comp Neurol 337:446-460.

Schoofs L, Veleert D, vanden Broeck J, de Loof A. 1997. Peptides in the locusts, Locusta migratoria and Schistocerca gregaria. Peptides 18:145156.

Schulte C, Kreissl S, Rathmayer W. 1996. A new type of common modulatory motoneurone in the locust? In: Elsner N, Schnitzler, editors. Proceedings of the 24th Göttingen Neurobiology Conference. Stuttgart: G. Thieme. p 583 .

Siegler MVS, Pousman CA. 1990. Motor neurons of grasshopper metathoracic ganglion occur in stereotypic anatomical groups. J Comp Neurol 297:298-312

Skiebe P, Schneider H. 1994. Allatostatin peptides in the crab stomatogastric nervous system: inhibition of the pyloric motor pattern and distribution of allatostatin-like immunoreactivity. J Exp Biol 194:195208.

Snodgrass RE. 1929. The thoracic mechanism of a grasshopper, and its antecedents. Smithson Misc Coll 82:1-111.

Stay B, Tobe SS, Bendena WG. 1994. Allatostatins: identification, primary structures, functions and distribution. Adv Insect Physiol 18:267-338.

Steffens GR, Kutsch W. 1995. Homonomies within the ventral muscle system and the associated motoneurons in the locust, Schistocerca gregaria (Insecta, Caelifera). Zoomorphology 115:133-150.

Stephens PJ, Govind CK. 1981. Peripheral innervation fields of single lobster motoneurons defined by synapse elimination during development. Brain Res 212:476-480.
Stevenson PA, Pflüger HJ, Eckert M, Rapus J. 1992. Octopamine immunoreactive cell populations in the locust thoracic-abdominal nervous system. J Comp Neurol 315:382-397.

Stokes DR. 1987. Insect muscles innervated by single motor neurons: structural and biochemical features. Am Zool 27:1001-1010.

Swales L, Evans PD. 1994. Distribution of myomodulin-like immunoreactivity in the adult and developing ventral nervous system of the locust Schistocerca gregaria. J Comp Neurol 343:263-280.

Taghert PH, Goodman CS. 1984. Cell determination and differentiation in identified serotonin-immunoreactive neurons in the grasshopper embryo. Dev Biol 92:489-506.

Tyrer NM, Gregory GE. 1982. A guide to the neuroanatomy of locust suboesophageal and thoracic ganglia. Phil Trans $\mathrm{R}$ Soc London B 297:91-123.

Veelaert D, Schoofs L, Tobe SS, Yu CG, Vullings HGB, Couillard F, de Loof A. 1995. Immunological evidence for an allatostatin-like neuropeptide in the central nervous system of Schistocerca gregaria, Locusta migratoria and Neobellieria bullata. Cell Tissue Res 279:601-611.

Vitzthum H, Homberg U, Agricola H. 1996. Distribution of Dip-allatostatin I-like immunoreactivity in the brain of the locust Schistocerca gregaria with detailed analysis of immunostaining in the central complex. J Comp Neurol 369:419-437.

Wall JB, Taghert PH. 1991. Segment-specific modifications of a neuropeptide phenotype in embryonic neurons of the moth, Manduca sexta. $\mathrm{J}$ Comp Neurol 309:375-390.

Walther C, Schäfer S. 1988. FMRFamide-like immunoreactivity in the metathoracic ganglion of the locust (Schistocerca gregaria). Cell Tissue Res 253:489-491.

Walther C, Schiebe M, Voigt KH. 1984. Synaptic and non-synaptic effects of molluscan cardioexcitatory neuropeptides on locust skeletal muscle. Neurosci Lett 45:99-104.

Walther C, Zittlau KE, Murck H, Voigt K. 1998. Resting membrane properties of locust muscle and their modulation. I. Actions of the neuropeptides YGGFMRFamide and proctolin. J Neurophysiol 80:771784

Watson AHD. 1984. The dorsal unpaired median neurons of the locust metathoracic ganglion: neuronal structure and diversity, and synapse distribution. J Neurocytol 13:303-327.

Watson AHD, Burrows M, Hale JP. 1985. The morphology and ultrastructure of common inhibitory motor neurons in the thorax of the locust. $J$ Comp Neurol 239:341-359.

Wiens TJ, Rathmayer W. 1985. The distribution of the common inhibitory neuron in brachyuran limb musculature. I. Target muscles. J Comp Physiol A 156:305-313.

Witten JL, O'Shea M. 1985. Peptidergic innervation of insect skeletal muscle: immunochemical observations. J Comp Neurol 242:93-101.

Worden MK, Kravitz EA, Goy MF. 1995. Peptide $F_{1}$, an N-terminally extended analog of FMRFamide, enhances contractile activity in multiple target tissues in lobster. J Exp Biol 198:97-108. 